\title{
Mercado para Produtos Reciclados à Base de PET/HDPE/lonômero
}

\author{
Elen B. Pacheco e Carlos A. Hemais
}

Resumo: A expansão do mercado de poli(tereftalato de etileno) (PET), considerada um fenômeno mundial, está acontecendo no Brasil. Hoje, o principal mercado para o PET é o de bebidas carbonatadas. $\mathrm{O}$ uso de PET em lugar do vidro vem trazendo inúmeras vantagens, incluindo menor peso, maior resistência ao impacto e menores custos de transporte. Foram estudados possíveis mercados para a mistura PET/HDPE, na proporção de 75/25, acrescida de uma pequena quantidade de compatibilizante. Os resultados do estudo indicam que possíveis mercados para o mistura poderá incluir o de embalagens para usos especiais e partes de automóvel.

Palavras-chave: Reciclagem, mercado, PET, HDPE, PET/HDPE.

\section{Introdução}

Esta última década foi particularmente importante no que se refere à conscientização das pessoas sobre os danos que o uso indiscriminado dos recursos pode causar ao meio ambiente. Essa conscientização levou o consumidor a assumir uma atitude mais crítica em relação às suas opções de consumo. Características de produtos, que até há pouco tempo não eram consideradas essenciais no processo de escolha, passaram a representar um peso na percepção das pessoas em seus atos de compra. Surge um novo elemento a nortear a decisão do comprador e produtos com características de preservação ambiental, isto é, biodegradáveis, não-tóxicos, feitos com matériaprima reciclada, entre outras, passaram a ser vistos de forma bastante favorável.

Em uma economia globalizada, na qual o ambiente competitivo é cada vez mais acirrado, as empresas necessitam de vantagens diferenciais para permanecerem no mercado. Assim, o mercado passou a ser mais exigente e privilegia a escolha de produtos de companhias que utilizem tecnologias de produção e métodos de gerenciamento que preservem o meio ambiente. A entrada em vigor do conjunto de normas ambientais ISO 14.000 (International Standardization Organization) veio fortalecer ainda mais essa preocupação com o meio ambiente. Deve-se ressaltar que, em paralelo à preocupação ecológica, existe todo o aspecto financeiro, pois, em futuro breve, a falta de preocupação com o aspecto ambiental pode trazer prejuízos vultosos para as companhias.

As modificações observadas no consumidor influenciaram a criação de novas tecnologias que não prejudiquem o meio ambiente e levem em consideração o aspecto competitivo do mercado e custos correspondentes. E com esses conceitos em 
mente, foi desenvolvido o presente trabalho, com enfoque na reciclagem de materiais pós-usados.

A consciência ecológica é fruto das necessidades do ser humano. Um dos aspectos mais preocupantes de agressão ao meio ambiente é a forma descontrolada como é feita a deposição do lixo. Agrava o problema referente ao espaço físico que ocupa esses depósitos urbanos. Como nos países desenvolvidos não há mais espaço para a deposição do lixo, foram criados programas para tentar solucionar o problema. Em nosso caso, essa problemática da falta de espaço só é encontrada nos grandes centros urbanos. Por outro lado, ainda é incipiente a adoção de modelos de aterros sanitários para o lixo urbano e o que hoje efetivamente existe são áreas reservadas para tal fim, porém sem estarem preparadas para evitar que esse lixo seja um fator de agressão ambiental. A deposição de lixo feita em locais não preparados para recebê-lo gera em torno de si um vasto contingente populacional, que sobrevive tirando seu sustento da exploração do lixo, vivendo em condições sub-humanas e criando seus filhos nesses ambientes completamente inóspitos e insalubres.

Pode-se dizer que não há uma organização para o gerenciamento desse material pós-consumido e não há uma política consistente em relação à melhoria das condições de vida das populações que vivem em torno dos "lixões".

A reciclagem é considerada uma das alternativas mais importantes dentro do conceito de desenvolvimento sustentável definido pela Organização das Nações Unidas (ONU). O processo deve ser utilizado em dois casos:

1. quando a recuperação dos resíduos seja técnica e economicamente viável, bem como higienicamente utilizável;

2. quando as características de cada material sejam respeitadas.

A reciclagem é o resultado final de atividades intermediárias de coleta, separação e processamento, através da qual materiais pós-consumidos são usados como matéria-prima na manufatura de bens, anteriormente feitos com matéria-prima virgem. $\mathrm{O}$ sucesso da reciclagem está diretamente ligado a:

- fornecimento de matéria-prima;

- tecnologia de reciclagem;

- mercado diferenciado.
Assim, esses 3 pontos devem ser análisados. O estudo econômico da produção de PET, principalmente de embalagens, é importante pois a matériaprima da reciclagem é o material pós-consumido, produzido a partir de resina virgem. A avaliação do mercado de PET, virgem e reciclado, e os possíveis mercados para a mistura PET/HDPE, complementam esse estudo.

\section{Dados Econômicos}

A contabilização da quantidade de materiais a serem reciclados é de suma importância na viabilização econômica do processo.

\section{Poli(tereftalato de etileno) (PET)}

O PET, utilizado para obtenção de garrafa, entrou no mercado brasileiro nos anos 90, com a importação de poliéster grau garrafa. O principal produtor nacional de resina PET, para ser utilizado no processamento por sopro (PET grau garrafa), é a Rhodia-Ster, com a capacidade instalada em 1997 de 180.000 t/ano ${ }^{[1]}$. A Rhodia-Ster obtém o PET a partir do ácido tereftálico e utiliza o processo denominado pós-condensação no estado sólido para obtenção do grau garrafa.

$\mathrm{Na}$ Tabela 1 se encontra a capacidade instalada do Brasil no ano de 1997.

A produção nacional de PET teve início em 1989 e atende basicamente a um mercado de bebidas carbonatadas, que atualmente é o terceiro do mundo, perdendo somente para os Estados Unidos e México.

Observa-se que a capacidade do parque industrial brasileiro é insuficiente para atender aos usuários locais. Apesar da capacidade ociosa apresentada pelas empresas nacionais ser de cer-

Tabela 1. Capacidade instalada de produção de PET no Brasil em $1997^{[1]}$

\begin{tabular}{|c|c|c|}
\hline Empresa & Localização & $\begin{array}{c}\text { Capacidade instalada } \\
\text { (ton) }\end{array}$ \\
\hline Fibra Nordeste & BA & 7.920 \\
\hline Fairway & SP & 9.000 \\
\hline Polyenka & SP & 20.300 \\
\hline Rhodia-Ster & SP & 180.000 \\
\hline \multicolumn{2}{|c|}{ Total } & 217.220 \\
\hline
\end{tabular}


ca de $34 \%$, o país está importando praticamente a mesma quantidade de PET produzido localmen$\mathrm{te}^{[2]}$.

Com relação ao consumo, de 1990 a 1994, a evolução anual ficou em torno de 100\%. Em 1995, não foi observado esse acréscimo. E o acréscimo no consumo de 45\% no ano de 1996 sobre 1995 foi abaixo das expectativas do mercado. As empresas começaram o ano de 1996 com os estoques no máximo, e o consumo foi freado devido a problemas econômicos, o que levou a queda nos preços da resina. Houve super oferta e os preços caíram. A resina, que chegou a custar mais de US\$ 3.000,00 (1990) por tonelada, hoje varia de US\$ 1.200 a US\$ 1.300.

O PET grau garrafa, na avaliação da Eastman $^{[3,4]}$, representa apenas $15 \%$ do mercado mundial de poliéster, uma vez que a maior parte da produção desse polímero é destinada à produção de fibras (tecidos sintéticos). O PET grau têxtil é obtido em uma fase anterior ao do tipo destinado às embalagens rígidas, e esse grade tem custo inferior. Por essa razão, e por se tratar de um segmento maior, com a falta de algodão a demanda de fibra poliéster aumenta. Essa é uma das principais causas da indisponibilidade de poliéster e do preço elevado da resina em certas épocas. Esses problemas representam mais um incentivo à prática da reciclagem.

\section{Polietileno de alta densidade (HDPE)}

O polietileno de alta densidade é o termoplástico com maior número de fornecedores no país. Seu consumo aparente pulou de 290.000 t/a no início da década para aproximadamente 620.000 t em 1998, representando taxas de crescimento de $10 \%$ anuais. A capacidade instalada desse polímero está na Tabela $2^{[1]}$.

Tabela 2. Capacidade instalada de HPDE em $1997^{[1]}$

\begin{tabular}{|c|c|c|}
\hline Empresa & Localização & $\begin{array}{c}\text { Capacidade instalada } \\
\text { (ton) }\end{array}$ \\
\hline Ipiranga Petroquímica & $\mathrm{RS}$ & 335.000 \\
\hline OPP Polietilenos & BA & 170.000 \\
\hline Polialden & BA & 150.000 \\
\hline Politeno & BA & 165.000 \\
\hline Solvay Polietileno & SP & 82.000 \\
\hline Total & & 902.000 \\
\hline
\end{tabular}

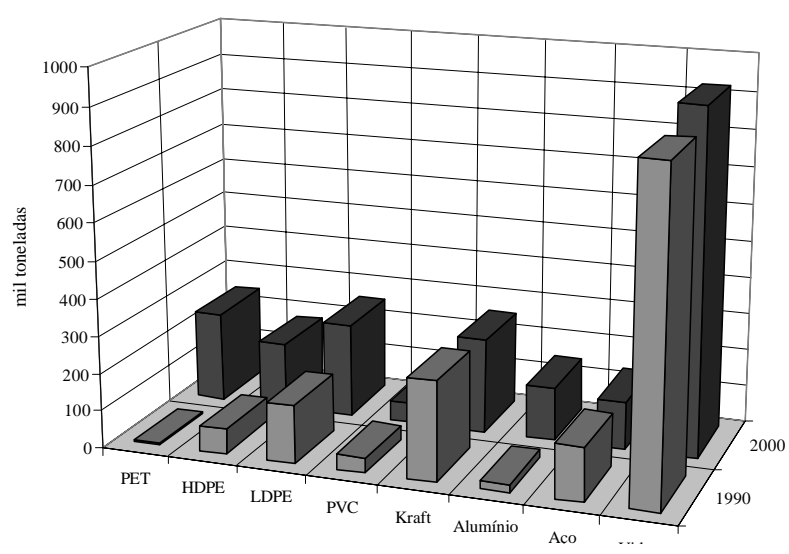

Figura 1. Mercado brasileiro de embalagens do ano 1990 em relação ao ano $2000^{[5]}$

O crescimento dessa resina pode ser considerado como linear, ou seja, apresenta uma estrutura no mercado já consolidada, o que ainda não é encontrado para o PET. O PET é uma resina mais jovem e seu mercado ainda não está sólido, principalmente pelo fato de ter tido uma entrada no mercado muito rápida.

A produção de HDPE utiliza $76 \%$ da capacidade instalada, ou seja, há $24 \%$ de ociosidade no setor.

\section{Mercado}

A avaliação do nicho do mercado em que o PET e o HDPE atuam também é de suma importância. Como esses materiais são destinados prioritariamente à fabricação de embalagem, seu tempo de vida útil, é pequeno, ou seja, o tempo de obtenção do artefato, colocação no mercado, utilização e sua deposição no lixo é de dias.

O desenvolvimento do mercado brasileiro de embalagens está apresentado na Figura 1.

O crescimento no mercado brasileiro do uso de embalagens de PET, de 1990 a 1997, foi na ordem de 50 vezes de 1990 a 1997. O HDPE é o terceiro material que mais cresceu na utilização em embalagens. As maiores taxas de crescimento, dentre os materiais plásticos, foram para o PET e para o $\mathrm{HDPE}^{[2]}$.

\section{PET reciclado}

O mercado de reciclagem é pouco conhecido, principalmente no Brasil. Na literatura nacional, 
há poucos dados e em alguns casos são conflitantes. Ainda existe no Brasil, muitas empresas não-oficiais no ramo de reciclagem. Dessa forma, as dificuldades são maiores em se fazer um estudo desse mercado. No exterior já se dá uma utilização mais nobre às fibras obtidas de PET reciclado. Por exemplo, fabricam-se calça jeans, alta moda e agasalhos com esse material.

A quase totalidade do PET reciclado é utilizado no ramo de mono ou multifilamentos. No Brasil não é encontrada uma aplicação mais nobre para esse material que apresenta propriedades de engenharia e preço de commodity. É interessante, do ponto de vista econômico e técnico, aproveitar essas oportunidades do mercado e dar ao PET reciclado uma utilização na qual suas propriedades de engenharia possam ser mais exploradas. Certamente, esse produto final terá melhor preço unitário no mercado que o de fibra obtida a partir do material reciclado. E os artefatos obtidos a partir de material pós-consumidos podem ser mais baratos que os obtidos de resina virgem, caso houver uma otimização na coleta desse material a ser reciclado e uma diferenciação no mercado do produto final.

\section{Futuros mercados para PET/HDPE compatibilizada}

A mistura PET/HDPE: $75 / 25$ foi estuda neste trabalho. Essa mistura com alto teor de PET $(75 / 25)$ pode ser utilizada em um nicho de embalagens com problemas de permeabilidade, como, por exemplo, as embalagens de defensivos agrícolas e tanques de gasolina.

\section{Embalagens com problemas de permeação}

Atualmente, os tanques de gasolina feitos de plástico estão ganhando mercado substituindo aqueles feitos de metal. Vantagens óbvias, como redução de custos, de peso, maior resistência ao rompimento e maior facilidade de produção, pesam significantemente na sua escolha. Outra vantagem é a possibilidade de produzi-los em formas complexas, tornando-os capazes de se acomodar em reentrâncias e pequenos espaços, coisa impossível de se fazer com os tanques feitos de aço.

Os tanques de combustíveis feitos de HDPE, maior área de aplicação em moldagem por sopro na indústria automobilística, também apresentam problemas de permeabilidade. Os hidrocarbonetos incham o HDPE em torno de $5-10 \%$. Os coeficientes de difusão de hidrocarbonetos em HDPE são da ordem de $10^{-8} \mathrm{~cm}^{2} / \mathrm{s}$, resultando em uma velocidade de permeação de 8g/dia. Nos Estados Unidos, novos regulamentos requerem reduções significantes na permeação de hidrocarbonetos $(0,1 \mathrm{~g} / \mathrm{dia})$. Combustíveis contendo metanol parecem apresentar menor permeabilidade ${ }^{[6]}$. O mercado de tanques plásticos de combustível movimenta em torno de 800 toneladas/mês de $\mathrm{HDPE}^{[7]}$

As embalagens plásticas para produtos químicos (produtos de limpeza e defensivos agrícolas), normalmente feitas de HDPE, sofrem esse mesmo problema de permeação. Os frascos plásticos permeáveis a solventes e gases, hermeticamente tampados, adquirem aparência "chupada", pois sofrem colapso devido à gradual formação de vácuo interno causado pela perda de material. As soluções de cloro para tratamento de piscinas podem perder quase todo o agente ativo ao serem envasadas em embalagens de HDPE.

O caso mais problemático é o de defensivos agrícolas, que são comercializados em veículos líquidos orgânicos. O vazamento de vapores tóxicos acarreta riscos de segurança e de saúde a quem os manuseia. As embalagens de defensivos agrícolas são de grande importância econômica para nosso país, que mantém grande atividade agrícola. A manipulação de defensivos é muito problemática devido a contaminações por parte dos trabalhadores rurais. Somente no Brasil foram consumidas em 1996 aproximadamente $40 \mathrm{mi}$ lhões de embalagens de defensivos ${ }^{[8]}$.

Agravando o problema, sabe-se que o consumidor brasileiro não é exigente e aceita produtos de péssima aparência, oferecidos em embalagens colapsadas.

São apresentadas duas soluções adotadas pelo mercado para resolver o problema e uma proposta pelo presente trabalho:

\section{a) Uso do processo de fluoretação ${ }^{[9]}$}

O tratamento superficial dos frascos de HDPE com gás flúor eleva a impermeabilidade da resina a fluidos orgânicos. Não há restrições para a reciclagem de frascos de HDPE fluoretado. 
Há dois processos de fluoretação:

1. Processo descontínuo: o frasco previamente soprado é reaquecido e submetido a ambiente rico em flúor (mistura de 1-3\% em volume de flúor em nitrogênio) no interior de uma câmara hermética durante alguns minutos. O flúor reage superficialmente com a resina, levando à substituição parcial de átomos de hidrogênio do polímero pelos de flúor. A macromolécula fluoretada diminui a permeabilidade a solventes e gases orgânicos.

2. A outra técnica consiste na injeção de flúor diluído em nitrogênio durante a produção dos frascos, ainda na sopradora.

Embora o tratamento da superfície interna em recipientes de HDPE com gás flúor tem reduzido a permeabilidade a fluídos orgânicos, estudos mostram que a durabilidade desse tratamento não tem vida longa. O flúor é um produto caro e importado e somente os portos de Santos e Rio de Janeiro são qualificados para o seu desembarque. A alta toxidade do flúor exige medidas de segurança extremas que são responsáveis pelo encarecimento do transporte e da unidade de fluoretação. O transporte rodoviário é feito em container acompanhados de batedores em todo o trajeto. No caso dos tanques de gasolina, acresce o fato de que a composição da gasolina comercializada no Brasil apresentar álcool, cuja presença pode piorar o desempenho dos tanques fluoretados. Assim, podese concluir que a fuoretação não parece ser a melhor solução para os problemas de permeabilidade.

\section{b) Uso de materiais multicamadas}

Outra possibilidade para minimizar o problema de permeabilidade seria com a utilização do artefatos obtidos por coextrusão. O material final é composto por várias camadas, sendo que algumas são mais impermeáveis ao produto químico em questão. Um exemplo desse processo é o que já está ocorrendo no Brasil na obtenção de tanques de gasolina nas montadoras da Volkswagem/ Audi no Paraná. O tanque é moldado com 6 camadas: HDPE, HDPE regranulado (recuperado), adesivo, poli(etileno-co-acetato de vinila) hidrolizado (EVOH) e HDPE pigmentado. A permeabilidade do tanque é em torno de $0,2 \mathrm{~g} /$ dia. Porém, também como a solução acima apresenta dificuldades, como com a nova composição passa-se a exigir formulações mais nobres como ao de adesivos e EVOH, respondendo a um incremento entre 20 a $30 \%$ no custo de matéria-prima. Não esquecendo das despesas com relação ao equipamento que é de $60-70 \%$ maiores que de uma sopradora convencional; e, a produção é mais lenta $^{[7]}$.

\section{c) Uso da mistura PET/HDPE/compatibilizante}

O uso de frascos soprados obtido a partir de uma mistura de PET/HDPE/compatibilizante na proporção $75 / 25$ poderia solucionar esses problemas tão graves: a permeabilidade do HDPE poderia ser melhorada com a adição do PET, e a processabilidade do PET com a adição do HDPE. Esse material poderá ser processado por uma extrusora-sopradora, processo mais barato de obtenção de artefatos ocos.

O PET é resistente a muitos produtos quími$\cos ^{[10]}$, tais como, alcoóis (metanol, etanol, glicol, glicerina), hidrocarbonetos ésteres/aldeídos (alifáticos, benzeno, tolueno, xileno, tricloetileno, tetracloreto de carbono, acetato de etila, acetaldeído, formaldéido), ácidos (fórmico 50\%, clorídríco $10 \%$, nítrico $10 \%$, sufúrico $10 \%$, acético, fosfórico (seco), ácido salícilico), sais (cianetos, fluoretos, bicromatos) e outros (parafinas, canfora, óleo de oliva, água oxigenada, mercúrio, éter, hidróxidos de sódio $10 \%$ ).

As misturas PET/HDPE: 75/25 compatibilizadas podem ser utilizadas nos seguintes mercados de embalagens em que a transparência não é requerida, tais como produto de limpeza, defensivos agrícolas, lubrificantes, thinner, óleo de linhaça, removedores de manchas, querosene e tintas. Também os tanques de gasolina são um mercado promissor para as misturas em questão.

\section{Conclusão}

As misturas preparadas em laboratório se mostraram promissoras para ocupar nichos de mercado específicos, quais sejam, o de embalagens para usos específicos e o de tanques de combustível. Todos os mercados propostos são de artefatos que não entram em contato com alimentos, o que faci- 
litaria a legalização da utilização de material reciclado.

A viabilidade econômica só é válida quando feita com dados de uma realidade de uma planta piloto, o que ainda não ocorreu neste trabalho. A priori, sabe-se que a matéria-prima, composta de plástico pós-consumido, apresenta um custo baixo em relação às virgens, em torno de $60 \%$. Os equipamentos que podem ser utilizados para o sopro das embalagens de mistura PET/HDPE: 75/25 são os mais simples, extrusora e sopradora.

Os tanques de gasolina que podem ser obtidos a partir de PET pós-consumido e HDPE na proporção $75 / 25$ pode ser confeccionado por processo convencional de rotomoldagem.

As opções propostas são ideais para pequenas e médias empresas, pois são soluções mais baratas e são passíveis de serem fabricados com equipamentos menos sofisticados.

\section{Agradecimentos}

CAPES, Hoechst, Polialden, Du Pont

\section{Referências Bibliográficas}

1. Anuário da Industria Química Brasileira; Associação Brasileira da Industria QuímicaABIQUIM, São Paulo, SP(1998);

2. Anon - Plásticos em Revista, 436, 68-112 (1999);

3. Sino,M.A - Plástico Moderno, 266, 35-42 (1996);

4. Anon.- Embanews, fev., 30-2 (1995);

5. Torres, R - Palestra , IMA/UFRJ, RJ (1998);

6. Naarrula, C. K.;.Allison, J. E.; Bauer, D. R.; Gangdhi, H. S. - Chemtech, nov., 48-68 (1996);

7. Anon - Plásticos em Revista, 433, pg. 2021(1998);

8. Anon - Cempre informa, 28, p.3 (1996);

9. Nothenberg,M. - Plástico Moderno 275, 22-32 (1997);

10. Oliveira, L.M. - Seminário, 30/10/97, Campinas, SP (1997), 